\title{
Cinco décadas de Marketing
}

exame da história do marketing no Brasil revelaum processo de adaptação às diferentes fases da economia e aos diferentes momentos do mundo empresarial. Com o tempo, abordagens centradas em vendas foram cedendo espaço a estratégias integradas de marketing. Hoje, as maiores influências sobre o desenvolvimento da atividade vêm das tecnologias de informação e telecomunicação, das mudanças no perfil dos consumidores e da redefinição das fronteiras de mercado.

por Sérgio Ricardo Góes Oliveira FGV-EAESP

U ma disciplina, em cinqüenta anos de existência, pode alegar história? Há dez anos, essa questão era formulada em um artigo publicado pela RAE - Revista de Administração de Empresas. 0 foco era a história do marketing no Brasil. Seu autor, o professor Raimar Richers, da EAESP, um dos precursores do campo no país.
O Brasil que serviu de pano de fundo para o texto original do professor Richers mudou bastante nesta última década. 0 mesmo pode ser dito com respeito à área de marketing, cujos desenvolvimentos mais recentes sugerem ter se transformado em uma força decisiva para a sobrevivência das empresas. 
Este artigo retoma e estende o texto de Richers. Além de relembrar os iniciadores da área e as principais influências sobre a formação de um conhecimento mercadológico no país, analisa as principais mudanças dos últimos dez anos, levantando sete desafios para o futuro.

Os precursores. 0 nascimento da disciplina de Marketing no Brasil confunde-se com a própria história da Escola de Administração de Empresas de São Paulo (EAESP). Essa história começa em 1954, quando a Fundação Getulio Vargas firmou um convênio de cooperação com a Michigan State University, que resultou na vinda de uma equipe de professores daquela instituição para o Brasil. Entre eles, estava o primeiro professor de Marketing da escola e do próprio país, Olé Johnson.

Com o passar do tempo, outros professores norte-americanos vieram para o Brasil, com o intuito de contribuir com a formação de um corpo local de professores de
Marketing. Entre eles, Dole Anderson, Donald Taylor e Leo Erickson. Anderson foi um dos responsáveis pela criação do Centro de Pesquisa e Publicações da EAESP, que gerou, além da RAE, o primeiro livro-texto de Marketing brasileiro: Administração Mercadológica: Princípios e M étodos. Os desafios desses precursores não foram poucos. Eles foram os responsáveis pela tradução, para a realidade local, de conceitos clássicos da área, os quais já eram praticados nos Estados Unidos.

Para os professores de vanguarda da EAESP - Affonso Arantes, Bruno Guerreiro, Gustavo de Sá e Silva, O rlando Figueiredo, Polia Lerner Hamburger e Raimar Richers - , o marketing era um conjunto integrado de funções. Richers desenvolveu um modelo que relacionava a posição de marketing dentro da empresa com seu ambiente, resultando no conceito dos " 4 As" - análise, adaptação, ativação e avaliação -, um complemento do tradicional conceito de marketing, denominado "4Ps", também destinado a integrar as diversas funções mercadológicas.

Décadas decinqüenta e sessenta. 0 marketing nasceu no Brasil, na década de cinqüenta, em um contexto de baixa oferta de mercadorias, mercado restrito e número pequeno de empresas. Os setores agrícola e comercial dominavam a economia. 0 setor industrial era ainda pouco desenvolvido eatendia basicamente às necessidades locais.

0 consumidor, por sua vez, não estava preparado para o consumo de produtos industriais sofisticados. Absorvia-se qualquer tipo de mercadoria, sem questionar a qualidade. Nesse contexto, as empresas prosperavam mais devido a uma demanda pouco criteriosa e passiva do que em função de uma estratégia planejada de adaptação ao mercado.

Essa condição se manteve praticamente inalterada até o governo Juscelino Kubitschek. A partir desse momento, o processo de industrialização tomou impulso. Tendo como base uma política de substituição de importações e relativo protecionismo, deu-se a criação de uma infra-estrutura e a formação de indústrias de base, que passou a atrair investimentos estrangeiros. 
0 crescimento foi impulsionado pelo enorme potencial de um mercado jovem. No final da década de sessenta, o conceito de "obsolescência planejada" traduzia bem o espírito da época: buscar incessantemente o desenvolvimento e o lançamento de novos produtos, mesmo que os consumidores ainda preferissem as versões antigas.

A industrialização levou ao aumento da oferta de produtos. Surgiram "produtos-vedete", como os eletrodomésticos, entre eles o aparelho de televisão. 0 mesmo processo fez crescer a concorrência, o que por sua vez levou os profissionais de mercado a se preocuparem cada vez mais com o consumidor.

Apesar da evolução do contexto, nesse período o conceito de marketing integrado era ainda pouco praticado. A ênfase era na atividade de vendas. 0 pressuposto dominante era que o sucesso da empresa relacionava-se fundamentalmente à sua capacidade de venda.

Tal orientação para vendas era facilitada e incentivada pela existência de um mercado comprador, com consumidores ávidos pela aquisição de mercadorias, que até há pouco tempo sequer imaginavam existir. Os produtos eram cada vez mais associados a símbolos de status e prestígio, e o consumidor não media esforços para adquiri-los, o que freqüentemente o levava a contrair dívidas.

Década de setenta. U ma situação de relativo equilíbrio perdurou praticamente por toda a década de sessenta e avançou até a década de setenta, o período do "milagre econômico". A política de afrouxamento fiscal e cambial do governo militar havia criado uma situação de relativo conforto para as classes mais altas, que via seu poder aquisitivo crescer ininterruptamente.

No entanto, o consumidor passou a agir de forma mais consciente; começou a comparar preços, a ficar mais atento à qualidade dos produtos e a cuidar de forma mais atenta do orçamento familiar.
Nesse período, o foco do marketing deixou de ser vendas e passou para a propaganda, realizada quase que exclusivamente por meio de mídias eletrônicas. De forma complementar, as empresas começaram a definir seus públicos-alvos por meio de estratégias de segmentação e com 0 apoio de pesquisas de mercado. A idéia dominante era que diferentes grupos de consumidores possuíam diferentes perfis e interesses, e estes precisavam ser identificados e atendidos. A maneira de fazer isso era comunicando-Ihe a existência do produto certo, por meio da publicidade.
O marketing nasceu no Brasil, na década de cinqüenta, em um contexto de baixa oferta de mercadorias, mercado restrito e número pequeno de empresas. Os setores agrícola e comercial dominavam a economia. 0 setor industrial era ainda pouco desenvolvido e atendia basicamente às necessidades locais. foi um período áureo, no qual as empresas investiam grandes verbas e apostavam no retorno. A fórmula geral consistia em ter um produto atraente, o que não era difícil, em função da demanda aquecida; ter uma mensagem que atingisse 0 consumidor, o que se tornou viável pela rápida disseminação e popularização da TV; e ter uma agência criativa, com bom domínio de metodologias quantitativas e conhecimento de mercado, capaz de produzir boas peças publicitárias. Essa fórmula criou a fantasia da prática do marketing perfeito. 0 cenário, entretanto, mudaria severamente nos momentos posteriores.

Década de oi tenta. A profunda crise que ocorreu na década de oitenta, também chamada de "década perdida", caracterizou-se por um regime de altas taxas inflacionárias com alternância de momentos de crescimento e momen- 
Se você não tem um Volkswagen, coloque isso atrás da orelha.

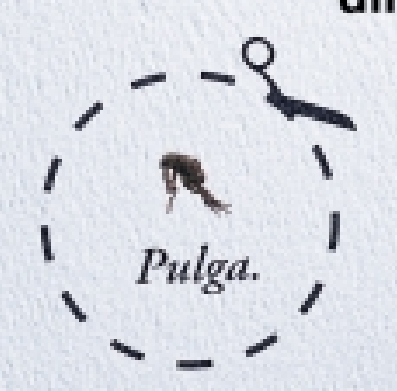


Está sentindo aquela coceirinha para comprar um carro novo? Então, cuidado. Se não for um Volkswagen, essa coceira pode muito bem ser uma pulga atrás da orelha. E falando no seu ouvido: é melhor comprar um Volkswagen, é melhor comprar um Volkswagen, é melhor comprar um Volkswagen. Porque até mesmo ela sabe que um Volkswagen é um carro mais durável, robusto e confiável do que os outros.

Mas como? Se carros são feitos basicamente dos mesmos materiais, das mesmas matérias-primas, dos mesmos componentes, como a gente consegue isso? Simples: fazendo carros mais bem-feitos. Aqui, as peças sã̃o selecionadas à exaustão. Para a Volkswagen, milímetros sầo quilômetros: qualquer imperfeição, por minúscula que seja, e a peça é descartada. $\hat{E}$ o que dá querer encarar o controle de qualidade mais rigoroso do mundo.

Depois, tudo é montado de um jeito que só a tecnologia alemã sabe fazer. Milimetricamente perfeito. Exaustivamente testado. Com precisão em cada detalhe. Tudo feito por gente que tem verdadeira obsessão pela qualidade.

Nada nos deixa mais satisfeitos do que um acabamento bem cuidado. Nada nos alegra mais do que um câmbio preciso, macio, impecável. Nada nos orgulha tanto quanto uma pintura que não desbota nem descasca. Nada nos realiza mais do que um motor que esbanja potência sem fazer barulho. Ou seja, um Volkswagen dá tantas alegrias para quem faz como para quem dirige. E você sabe: depois de milhares e milhares de quilômetros rodados, ele ainda tem o maior valor de revenda do mercado.

A gente sabe que carro é um bem precioso. Depois da casa, é o bem mais valioso que o brasileiro compra na vida. $\hat{E}$ uma imensa responsabilidade. Por isso, a gente faz questão de dar o melhor para que ele valha cada centavo que vocẻ paga.

Pense nisso. Ouça a pulga atrás da sua orelha. E antes de sair pulando de marca em marca, preste atenção em tudo o que a gente disse aqui. E prefira a marca que todo o Brasil conhece e confia.

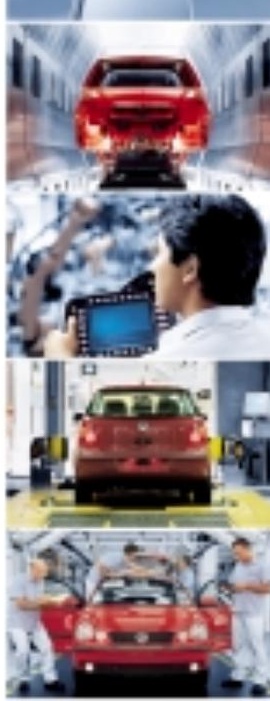


tos de recessão, o que contribuiu para tornar o consumidor mais inseguro e desconfiado. Em um momento de altos índices de inflação e corrosão salarial, a melhor estratégia pessoal era economizar e direcionar muito bem o uso do (restrito) orçamento familiar. Assim, os consumidores tornaram-se mais seletivos, o que representou novo desafio para as empresas. nais e nacionais. 0 fenômeno das aquisições só não foi maior porque a legislação local restringiu o controle acionário dos meios de comunicação de massa.

A propaganda, até então instrumento promocional hegemônico, sofreu grande evasão de recursos, principalmente nas mídias tradicionais, o que culminou com uma crise no setor. Em contrapartida, as ações de marketing promocional e de ponto-de-venda cresceram expressivamente.

$\mathrm{Na}$ década de noventa, começou a ficar claro que a integração das ações de marketing era vital. Exemplo desse fenômeno foi a perda de mercado que as agências de publicidade sofreram. Acostumadas a uma realidade confortável, na qual bastava uma boa peça publicitária em rede nacional de TV alcançar o consumidor, elas valorizavam pouco os diversos ins-

A crise levou a uma drástica redução na demanda de bens e no consumo. Em um ambiente de acirrada competitividade e escassez de recursos, o foco do marketing deslocou-se então da propaganda para o produto. As empresas passaram também a dar mais importância às preferências do consumidor. Com isso, ganharam popularidade as pesquisas de mercado. 0 foco era determinar como o produto poderia ser mais bem aceito. Os esforços das empresas se voltaram para a busca de soluções de adaptabilidade e adequação ao uso.

Década de noventa. Os anos noventa foram marcados por profundas transformações nos cenários político e econômico. A democracia se consolidou e o país começou a abrir suas fronteiras econômicas. Paralelamente, as privatizações, fusões e aquisições mudaram fortemente e "ecologia empresarial".

Grandes mudanças também ocorreram nas empresas prestadoras de serviços de marketing, quando grandes grupos internacionais absorveram as empresas regio- trumentos de comunicação que se desenvolveram no período, como o marketing direto, a Internet e as demais mídias digitais. Com isso, as agências de publicidade perderam espaço para novas empresas que se especializaram em práticas como marketing promocional, marketing direto e marketing cultural.

Enquanto isso, nas empresas, o conceito de markeação. 0 desafio para os profissionais de marketing passou a ser a integração de um número cada vez maior de instrumentos promocionais no desenho das estratégias de relacionamento com o consumidor. Se, por um lado, isso foi facilitado pela maior oferta de serviços especializados, por outro trouxe um desafio adicional aos departamentos de marketing, que passaram a ter de decidir com quais fornecedores deveriam criar e desenvolver suas ações. Dessa maneira, o esforço de gestão de diferentes fornecedores e agências, e a integração desses prestadores de serviços com as necessidades das empresas, passaram a ser preocupações prioritárias para os executivos de marketing. ting promocional passava a dominar as estratégias de 
Tril has para o futuro. N este ponto, devemos nos perguntar: que desafios deverão ser enfrentados pelos profissionais brasileiros de marketing nos próximos anos?

0 primeiro desafio relaciona-se à inclusão. 0 Brasil, como outros grandes países subdesenvolvidos - China, Índia, Malásia, África do Sul etc. - , conta com expressiva população que vive à margem do consumo. As grandes empresas parecem ter sido criadas e estruturadas para atender ao extrato da classe média. Seus profissionais são capazes de identificar necessidades e desenvolver produtos e serviços para públicos de médio e al to poder aquisitivo, porém costumam ter dificuldades quando se trata de compreender as necessidades de populações de baixa renda e atendê-las.

0 segundo desafio refere-se ao fenômeno que alguns críticos têm definido como "macdonaldização" ou "disneyficação": a "colonização" das mais diversas atividades, inclusive espaços esportivos e culturais, pelos conceitos de produção e consumo rápido (que transforma tudo em fast food) e pela "síndrome do parque temático" (que transmuta lojas em espaços teatrais). Essa tendência, que pode parecer divertida no primeiro momento, encontra seus limites pela própria condição de falsidade que carrega.

0 terceiro desafio refere-se à saturação. Embora vivamos em um país emergente, com mercados ainda pouco explorados e grandes oportunidades de crescimento, do ponto de vista do consumidor há um verdadeiro massacre de mensagens de promoção e vendas. A poluição visual dos outdoors, a invasão dos cinemas, das praias e de outros espaços públicos são sinais visíveis do fenômeno. 0 excesso pode levar à insensibilização do consumidor ou até mesmo criar certa antipatia pelas marcas que se prestam a tais práticas.

0 quarto desafio refere-se à privacidade. A evolução da tecnologia levou ao desenvolvimento das ferramentas de classificação e exploração de banco de dados, e estas à sofisticação das ações de marketing. Tal passo provavelmente vai se chocar com a evolução dos instrumentos de defesa do consumidor e, em especial, com a tomada de consciência em relação ao direito à privacidade. Esse contexto deverá constituir um desafio para o profissio- nal de marketing, que deverá buscar o equilíbrio entre máximo conhecimento do consumidor e mínima percepção de invasão do espaço privado.

0 quinto desafio relaciona-se à complexidade. $\mathrm{A}$ gestão mercadológica transformou-se, nos últimos anos, em uma rede complexa, que envolve mercados múltiplos, portfólios amplos de produtos e uma grande maIha de fornecedores e agentes de suporte. Hoje, devese gerenciar, simultaneamente, produtos, marcas, canais e relacionamentos. As ferramentas de apoio se sofisticaram, porém as competências para análise e tomada de decisão não acompanharam o aumento da complexidade ambiental.

0 sexto desafio refere-se à sensibilidade. Profissionais de marketing são hoje o que o ex-secretário do trabalho norte-americano Robert B. Reich denominou "analistas simbólicos": indivíduos capazes de criar modelos abstratos para lidar com realidades complexas, que têm a sensibilidade e os recursos para decodificar as necessidades explícitas e implícitas do consumidor, além da capacidade de desenvolver soluções apropriadas.

0 sétimo desafio refere-se à conduta ética. 0 s escândalos financeiros ocorridos em grandes empresas norte-americanas e européias colocaram a questão ética novamente na agenda dos executivos. Entretanto, o tema não deve ser tratado apenas no que se refere à dimensão financeira. Toda decisão de negócio, inclusive aquelas mercadológicas, deve contemplar uma análise de impactos sobre os indivíduos, a comunidade e o meio ambiente.

A mercadologia no mundo é um campo adolescente, talvez ainda impúbere no Brasil. Age, na maior parte das vezes, com visão de curto prazo, visando à satisfação imediata. É incapaz de superar a mais tosca instrumentalidade e perceber impactos em médio e longo prazos. Cabe aos profissionais de marketing das escolas e das empresas responder aos desafios anotados e traçar a agenda desse vigoroso campo para os próximos anos.

Sérgio Ricardo Góes Oliveira

Doutorando em Marketing na FGV-EAESP

E-mail: sergiogoes@gvmail.br 